Sādhanā Vol. 40, Part 2, April 2015, pp. 379-394. (C) Indian Academy of Sciences

\title{
Fuzzy-logic based learning style prediction in e-learning using web interface information
}

\author{
L JEGATHA DEBORAH ${ }^{1, *}$, R SATHIYASEELAN ${ }^{2}$, \\ S AUDITHAN $^{3}$ and P VIJAYAKUMAR ${ }^{1}$
}

${ }^{1}$ Department of Computer Science and Engineering, University College of Engineering Tindivanam, Melpakkam - 604 001, India

${ }^{2}$ Anna University, Chennai-600 025, India

${ }^{3}$ Department of ECE, Prist University, Thanjavur-613 403, India

e-mail: blessedjeny@gmail.com; vijibond2000@gmail.com;

Sathiyaseelanrec@gmail.com; saudithan@gmail.com

MS received 24 November 2013; revised 16 November 2014; accepted 22 December 2014

\begin{abstract}
The e-learners' excellence can be improved by recommending suitable e-contents available in e-learning servers that are based on investigating their learning styles. The learning styles had to be predicted carefully, because the psychological balance is variable in nature and the e-learners are diversified based on the learning patterns, environment, time and their mood. Moreover, the knowledge about the learners used for learning style prediction is uncertain in nature. This paper identifies Felder-Silverman learning style model as a suitable model for learning style prediction, especially in web environments and proposes to use Fuzzy rules to handle the uncertainty in the learning style predictions. The evaluations have used the Gaussian membership function based fuzzy logic for 120 students and tested for learning of C programming language and it has been observed that the proposed model improved the accuracy in prediction significantly.
\end{abstract}

Keywords. E-learning; e-contents; learning styles; Felder-Silverman learning style model; fuzzy rules.

\section{Introduction}

E-Learning is a convenient learning methodology as defined by Chen et al (2004), refers to the delivery of information and knowledge to anybody, anytime and anywhere to reduce time, effort, and cost. The intentions of e-learning are basically fivefold namely flexibility, personalized learning, knowledge development, intelligent tutoring system and continual assessment of learners' progress in e-learning. Moreover, the success or failure of the e-learning framework

${ }^{*}$ For correspondence 
is decided by many factors, including the learning objects, delivery of learning objects, related information retrieval, knowledge management, performance evaluation, and the impact of learning styles which vary from one learner to another learner. According to Butler (1986), learning style is a particular way in which an individual learns. Enormous techniques and instruments, namely questionnaires, interviews, and disclosure of profile information have been identified in the past to predict the learning styles of the learners learning through any kind of environment. These kinds of techniques for identification may be suitable for the traditional classroom setting environment. However, the scenario of e-learning is completely different due to the factors of nullified face-face interactions, body language understanding, constant progress monitoring, effective motivation, and improved self-efficacy. The learning styles differ based on two important factors - static and dynamic factors and these factors are discriminated based on several attributes as mentioned in table 1. Based on the dimensions provided in table 1, the learning theory and the learning style models are correlated. Therefore, specialized techniques must be utilized in order to identify the individual learning styles and to recommend suitable e-contents available in the e-learning servers to the learners who are learning through web environments.

Table 1 shows some of the important factors for identifying the learning styles of the learners. The two prominent factors are the static and dynamic factors. These factors were chosen based on the empirical tests present in the related works. The static factors are the learning models in which learners' learning styles are constant and do not change in any circumstances. In contrast, the dynamic factors are the ones in which the learning styles and their preferences change from time to time due to their cognitive and psychological parameters.

\subsection{Overview of educational systems}

A new revolution in internet education is called e-learning or web-based learning (Chen et al 2004). The various educational systems that are available are offline learning system, e-learning systems, intelligent tutoring system, adaptive learning system, and learning systems with learning styles prediction. Table 2 provides an overview of the existing educational systems with appropriate descriptions. The main objective of this paper is to handle the uncertainty existing in the earlier models, thereby increasing the accuracy in predicting the learners based on their learning styles in e-learning.

This is achieved by categorizing the learners present in the unknown category of Sanders \& Bergasa-Suso (2010) model into active, medium active, medium reflective, and reflective using fuzzy membership functions (Swati Chaudhari \& Manoj Patil 2014). There are many advantages of the proposed model. First, it has the ability to predict the learning styles based on not only the web usage information but also on their original profile information. Second, the proposed model makes use of fuzzy membership functions. Therefore, the precise reasoning in assessing the learners based on their learning styles is achieved. Third, it has the ability to accurately assess the learners based on their learning styles by classifying the learners into two of the four categories, namely active, medium active, medium reflective, and reflective.

\subsection{Learning styles overview}

A deep understanding of one's own way of learning can lead to a great personal empowerment and self-confidence and this is identified by analyzing the behavior of the learners involved in an e-learning. One of the techniques employed for identifying such behavior of the learners in elearning is their usage of the web browsing activity. Moreover, the knowledge about the learners 
Table 1. Factors influencing learning style prediction.

\begin{tabular}{|c|c|c|c|c|}
\hline Type of factor & Dimensions & Learning theory & $\begin{array}{l}\text { Underlying principle } \\
\text { of learning theory }\end{array}$ & Existing learning style models \\
\hline \multirow[t]{4}{*}{ Static } & Personality type & Experimental theory model & $\begin{array}{l}\text { Learning based on } \\
\text { experiences only }\end{array}$ & $\begin{array}{l}\text { Kolb Model (Cornwell \& Manfredo } \\
\text { 1994; Kolb \& Kolb 2005) }\end{array}$ \\
\hline & & Behavioral theory model & $\begin{array}{l}\text { Learning based on only } \\
\text { behaviors of the individuals. } \\
\text { Study about how people } \\
\text { behave in new circumstances }\end{array}$ & $\begin{array}{l}\text { Honey and Mumford Model } \\
(2000)\end{array}$ \\
\hline & & Cognitive theory model & $\begin{array}{l}\text { Learning based on emotions } \\
\text { exposed to the environment }\end{array}$ & Gregorc model (Gregorc \& Ward 1977, 1985) \\
\hline & & Meta-learning theory model & $\begin{array}{l}\text { Acquire new information based } \\
\text { on perception, inquiry and } \\
\text { learning in safe and supportive } \\
\text { environment }\end{array}$ & Flemming VARK model (Fleming 2001) \\
\hline \multirow[t]{3}{*}{ Dynamic } & $\begin{array}{l}\text { Intelligence quotient } \\
\text { factors } \\
\text { Biological factors } \\
\text { Inherent interests }\end{array}$ & Personality model & $\begin{array}{l}\text { Learning based on five factor } \\
\text { OCEAN model [Openness, } \\
\text { Conscientiousness, Extraversion, } \\
\text { Agreeableness, and Neuroticism] }\end{array}$ & $\begin{array}{l}\text { Carl and Myers Brigg Indicator } \\
\text { model (McCaulley 2000; } \\
\text { Pittenger 2005) }\end{array}$ \\
\hline & & Intelligence theory model & $\begin{array}{l}\text { Learning based on intelligence } \\
\text { quotient factor }\end{array}$ & Howard Gardner (1999) \\
\hline & & $\begin{array}{l}\text { Neuropsychological theory } \\
\text { model }\end{array}$ & $\begin{array}{l}\text { Learning based on inherent } \\
\text { interests and the biological } \\
\text { changes due to environmental factors }\end{array}$ & Chris Jackson (2002) \\
\hline
\end{tabular}


Table 2. Overview of educational systems.

\begin{tabular}{|c|c|c|}
\hline Educational system & Description & Papers references \\
\hline $\begin{array}{l}\text { Traditional offline } \\
\text { learning system }\end{array}$ & $\begin{array}{l}\text { Instructors and learners learnt } \\
\text { course materials face-face in } \\
\text { a classroom setting }\end{array}$ & (Beck et al 2004; Dekker et al 2009) \\
\hline E-learning system & $\begin{array}{l}\text { Learners learn their course mate- } \\
\text { rials through electronic devices }\end{array}$ & $\begin{array}{l}\text { (Avouris et al 2005; Chen et al 2000, } \\
\text { 2004; Kakoty et al 2012) }\end{array}$ \\
\hline $\begin{array}{l}\text { Intelligent learning } \\
\text { system }\end{array}$ & $\begin{array}{l}\text { Learning activities are enhanced } \\
\text { through Artificial Intelligence } \\
\text { techniques like software agents, } \\
\text { page ranking, and machine } \\
\text { learning algorithms }\end{array}$ & $\begin{array}{l}\text { (Antunes 2008; Bake et al 2004; } \\
\text { Jegatha Deborah et al 2011a, b; } \\
\text { Wilges et al 2012; Garcia-Valverde } \\
\text { et al 2012) }\end{array}$ \\
\hline $\begin{array}{l}\text { Adaptive learning } \\
\text { system }\end{array}$ & $\begin{array}{l}\text { Learning objects can be modified } \\
\text { according to learners' preferences }\end{array}$ & $\begin{array}{l}\text { (Carver } \text { et al 1999; Ba-Omar et al 2007; } \\
\text { Bergasa-Suso et al 2005; Sanders \& } \\
\text { Bergasa-Suso 2010; Zhe Tang 2011) }\end{array}$ \\
\hline $\begin{array}{l}\text { Exclusive performance } \\
\text { assessment in e-learning }\end{array}$ & $\begin{array}{l}\text { Constantly monitoring the perfor- } \\
\text { mance of the learners in E-Learning }\end{array}$ & $\begin{array}{l}\text { (Anozie \& Junker 2006; Ayers et al 2009; } \\
\text { Barnes 2005; Chen \& Weng 2009) }\end{array}$ \\
\hline Blended learning & $\begin{array}{l}\text { Learning Content Management } \\
\text { and the learning are blended in } \\
\text { nature which is a combination } \\
\text { of traditional class room and } \\
\text { electronic learning }\end{array}$ & (Dias \& Diniz 2013) \\
\hline
\end{tabular}

is usually critical and uncertain. This paper exhibits the results for a quick analysis of the past learning style models (Jegatha Deborah et al 2014). The proposed model is based on the learning style preferences present in Felder Silverman learning style model (Felder \& Silverman 1988). Many works have been identified in the past based on this model (table 1). This paper specifically focuses on the analysis of the earlier model developed by Sanders \& BergasaSuso (2010) and it is enhanced to handle uncertainty in their model. According to Sanders \& Bergasa-Suso (2010), the learners are classified into any one of the three categories crisply as active, reflective, or "unknown". The unknown category derived in their model is considered to be uncertain and this issue has been resolved in our proposed model using Fuzzy Logic (Dias \& Diniz 2013; Swati Chaudhari \& Manoj Patil 2014). According to the proposed model, the "unknown" category in the existing model had been further classified. The proposed model can effectively classify all the target learners into any one of the four categories, namely active, medium active, medium reflective and reflective learners. For this purpose, a Gaussian membership function is used in the model, thereby effective classification of learners, based on their learning styles in e-learning environments can be achieved. The traditional Gaussian membership function is used due to various reasons (Elhag \& Ahmed 2013). They are: this function follows a normal distribution and the target applications tend to be normally distributed. Since, it follows a normal distribution it avoids the chances of high rate of data skewing.

The rest of the paper is organized as follows. Section 2 analyzes the working, merits and demerits of the existing learning style assessment techniques and models. Section 3 offers the working of the proposed Fuzzy-logic based learning style prediction in e-learning. Section 4 explains the experimental set up defined for the experiments handled and subsequently by the discussions and comparisons of the results. Section 5 precisely concludes the paper with the future scope of the work in progress. At the end, the fuzzy rules used in this paper are given as an Appendix A. 


\section{Related works}

Learning Styles produces a greater impact on the learning performances, especially in e-learning environments (Bergasa-Suso et al 2005; Sanders \& Bergasa-Suso 2010). The learning styles may differ for the same individual based on several factors like mood, time, course content and environmental factors. The major objective of learning style prediction is to assist the learners through recommendations on the appropriate e-contents available in e-learning servers. A new framework had been identified in the past which integrates the methodology of agents and learning capabilities. This systems focuses mainly on analyzing the performance rather than learning activities (Wilges et al 2012; Acampora et al 2011). The proposed fuzzy logic based indoor localization learning system is able to adapt online incrementally in a lifelong learning mode to deal with the uncertainties and changing conditions facing unknown indoor structures with a few days of calibration at zero-cost deployment with high accuracy (Garcia-Valverde et al 2012). Type-II fuzzy logic-based system was developed to suit e-learning environments for personalized learning. The system suits the adaptive nature of learners that facilitates individual knowledge delivery to the learners (Almohammadi \& Hagras 2013). The proposed learning architecture focus on the methodological approach based on Fuzzy logic to Select the Optimum Instructional style(s) for Designing a Specific E-learning system (MFSOI-DSE) for the benefit of the e-learners (Elhag \& Ahmed 2013). An expert system based on fuzzy logic and the subsequent inferences are developed in an e-learning environment. The major objective of the proposed system is basically on the evaluation system rather than the learning system (Kakoty et al 2012). This paper reports an attempt to achieve these results by exploiting an ontological representation of learning environment and an adaptive magnetic approach, integrated into a cooperative multi-agent framework. In particular, a collection of agents analyzes learner preferences and generate high-quality learning presentations by executing, in a parallel way, different cooperating optimization strategies (Swati Chaudhari \& Manoj Patil 2014). Several learning style assessment techniques and models were prevalent in the past. The generic categorizations of learning styles fall under the factors elaborated in table 1. This paper considers the learners' online activity information and some of the well known systems for learning styles prediction through such online activities are intelligent browser-based system (Bergasa-Suso et al 2005), and computer interface system (Sanders \& Bergasa-Suso 2010). The work proposed in this paper is an extension to the system developed by Sanders \& Bergasa-Suso (2010) who developed a new intelligent system and the proposed model has been evaluated and tested for E-Learning environments.

\subsection{Survey on learning styles models}

Numerous learning style models are prevalent based on different learning theories, namely experiential, behavioral, cognitive, biological, and psychological traits.

Table 3 shows a clear picture on the analysis of the existing learning style models. However, applying these models to the web based learning leads to a lot of challenges. Some of the challenges are that all these models prefer to acquire the learners' complete information and then could classify them (Guennoun \& Drira 2006). However, in reality, most of the information about the learners has vague information. Hence, it must be mandatory to acquire some effective techniques to draw conclusions even from incomplete data or information. The next challenge is that, all of these models assume that the instructor and the learners meet face-face very often and hence the learning styles could be predicted easily. Finally, the existing models consideras an important factor which is usually vague in nature. In order to understand the learners' 
Table 3. Existing learning style models.

\begin{tabular}{|c|c|c|c|}
\hline S. no. & Learning style models & Learning theory & Limitations \\
\hline 01. & $\begin{array}{l}\text { David Kolb model (Cornwell } \\
\& \text { Manfredo 1994) }\end{array}$ & Experiential learning theory & $\begin{array}{l}\text { Mixed empirical results and } \\
\text { low to motivate predictive } \\
\text { reliability }\end{array}$ \\
\hline 02. & $\begin{array}{l}\text { Honey and Mumford model } \\
(2000)\end{array}$ & Behavioral theory & $\begin{array}{l}\text { Assumed to acquire preferences } \\
\text { that are adaptive, either at will } \\
\text { or changing circumstances }\end{array}$ \\
\hline 03. & Gregorc model (Gregorc 1985) & Cognitive theory & $\begin{array}{l}\text { Some qualities and ordering } \\
\text { abilities are more dominant } \\
\text { within certain individuals }\end{array}$ \\
\hline 04. & $\begin{array}{l}\text { Flemming VAK model } \\
\text { (Fleming 2001) }\end{array}$ & Meta-learning theory & Low validity and reliability \\
\hline 05 . & $\begin{array}{l}\text { Dunn and Dunn model } \\
\text { (Dunn 1990; Dunn \& } \\
\text { Dunn 1989) }\end{array}$ & $\begin{array}{l}\text { Biological \& Experimental } \\
\text { theory }\end{array}$ & $\begin{array}{l}\text { Criticized for not considering } \\
\text { the differences among the } \\
\text { individuals }\end{array}$ \\
\hline 06. & Chris Jackson (Jackson 2002) & Neuro-psychological theory & $\begin{array}{l}\text { Contextual differences in the } \\
\text { dependent variable }\end{array}$ \\
\hline 07. & $\begin{array}{l}\text { Carl Jung and Myers Briggs } \\
\text { type indicator (McCaulley 2000) }\end{array}$ & Personality theory & Lacks convincing validity Data \\
\hline 08. & $\begin{array}{l}\text { Howard Gardner multiple } \\
\text { Intelligence (Gardner 1999) }\end{array}$ & Intelligence theory & $\begin{array}{l}\text { Detecting additional intelligen- } \\
\text { ces is not easy and is not well } \\
\text { suited for all types of individuals }\end{array}$ \\
\hline 09. & $\begin{array}{l}\text { Felder-Silverman Index of } \\
\text { learning styles (Felder \& } \\
\text { Silverman 1988) }\end{array}$ & Psychological theory & $\begin{array}{l}\text { Dependencies between two styles } \\
\text { exist and hidden dimensions present } \\
\text { in dataset produces a greater impact } \\
\text { on the identification }\end{array}$ \\
\hline
\end{tabular}

psychology, which is incomplete, it is desirable to use a rule based approach like neural networks or fuzzy logic which can effectively handle incomplete information as well.

\subsection{Works on offline learning style prediction using offline environment}

The next category of learning style prediction systems could effectively make use of internet education systems and are very suitable for many courses on the internet. However, these systems fail to consider the learner's capacity or provide any intelligent advice on potential websites. WebCT is the first internet educational system that could provide learning course materials through the web but cannot provide any intelligent technique which could consider the learner's capacity (Sanders 1993). The next suite of internet educational systems like INSPIRE (Papanikolaou et al 2002), ARTHUR (Gilbert \& Han 1999), AES-CS (Triantafillou et al 2002), LSAS (Yang et al 2013), CS388 (Carver et al 1999), and Tangow (Paredes \& Rodriguez 2002), could predict the learning styles of the learners effectively, but content adaptation was made based on previous knowledge, but these systems needed to assess the learners learning styles offline and questionnaire evaluation.

\subsection{Works on online learning style prediction using online environment}

The system developed by Bergasa-Suso et al (2005) is called AHA, which was a set of tools that overcame the difficulties of the systems described in Section 2.2. This set of tools is known 
as lessons from Bergasa-Suso et al (2005). The model proposed by him considered Felder Silverman learning style preferences as a base model to categorize the learners into any one of the four dimensions, namely active/reflective, sensing/intuitive, visual/verbal, and sequential/global. Therefore, iLessons is an important contribution for E-Learning by identifying the learners as either active or reflective for the first dimension. This model was satisfied when the learners tend towards a particular dimension most of the time. However, this scenario will not be true always. This condition was rectified subsequently, by the model developed by Sanders \& Bergasa-Suso (2010) known as a new intelligent system to categorize the learners into any one of the four dimensions described in Felder Silverman learning style model which had an effective user interface. According to this system, the learners were classified into three categories for the first dimension (active/reflective) as active, reflective, or unknown. The accuracy of classifying the learners in Sanders \& Bergasa-Suso (2010) work has increased to 81\% compared to the earlier work done by Bergasa-Suso et al (2005). However, this model can still be enhanced by resolving the unknown category of the learners. This kind of uncertainty in the inference found in the unknown category can be handled by introducing Fuzzy rules for effective classification of the learners learning through web environments.

\subsection{Analysis of related works}

From the analysis made, there were many internet educational systems which could effectively predict the learning styles through offline or questionnaires or through online activity information. In spite of good contributions offered by various researchers in predicting the learners learning styles through web usage information, it will be worthier if some machine learning algorithms are used for effective classification. Queries based on the degree of activeness or reflectiveness are not addressed in any of the existing recent models for accurate prediction of the learners. Hence, it is necessary to provide a rule-based approach like neural networks or fuzzy logic for effective classification of the learners' learning through web environments (Nebot et al 2006). Rule-based approaches are found to be more appropriate since the other traditional techniques do not address the issue of uncertainty very well. The model proposed in this paper makes use of Fuzzy membership functions which helps in identifying the degree of activeness or reflectiveness and also categorizes the learners in the unknown category of the existing models into active, medium active, medium reflective, and reflective types of learners (Lu et al 2007).

\subsection{Overview of Felder-Silverman learning style model (Felder \& Silverman 1988; Sanders \&} Bergasa-Suso 2010)

This learning style model is often used in technology-enhanced learning. This learning style model is usually preferred in web-based learning environment. The model is very useful because of the four dimensions of learning style preferences, which considers the technological aspects of the e-learning learners. The four dimensions for categorizing the learners are as follows:

(i) Active/Reflective: Active learners are active be themselves and their user activity across the web environments will be very fast, whereas the reflective learners slowly think about concepts and the user activity across the web environments will be usually very slow.

(ii) Sensing/Intuitive: Sensing learners try to learn the underlying facts, whereas intuitive learners prefer to identify relationships existing among the concepts.

(iii) Visual/Verbal: Visual learners prefer to learn through pictures, flow charts, and cartoons whereas verbal learners tend towards learning through textual representations 
(iv) Sequential/Global: Sequential learners learn through incremental learning, whereas global learners learn at a single scratch of time.

The proposed model concentrates on the first dimension of active/reflective since the learners learning through e-learning environments usually fall in either of the categories mentioned.

\section{Fuzzy-logic based learning style prediction system}

In this paper a new learning style identification system based on Fuzzy logic has been proposed. The proposed model is based on Felder Silverman learning style model that relies on psychological theory. The model is tested for the learners who are learning $\mathrm{C}$ programming language through E-learning environments. Figure 1 shows the architecture of the proposed fuzzy-logic based learning style prediction model. The proposed system uses the learners' web interface information and Felder Silverman learning style preferences as inputs.

\subsection{Inputs to the proposed prediction system}

The proposed model makes use of MediaWiki e-learning servers for the E-Learning contents to be posted in various formats. This E-Learning server in our model consisted of $\mathrm{C}$ programming language course contents in textual, audio, and video formats. The learner after proper authentication could access any type of contents that are available in Media Wiki E-Learning server. The target learners in our proposed model tend towards textual format of the course contents, and therefore our model was evaluated and tested for identifying the first dimension of Felder Silverman learning style preferences. The learners' during the authentication are asked to provide their original profile information for the purpose of learning style identification. Table 4 depicts the characteristics of the earlier learning style models that are used in various application domains.

Therefore, the learners are accurately classified based on their learning styles using their own profile information and their online web usage activity. To facilitate the experimental evaluation,

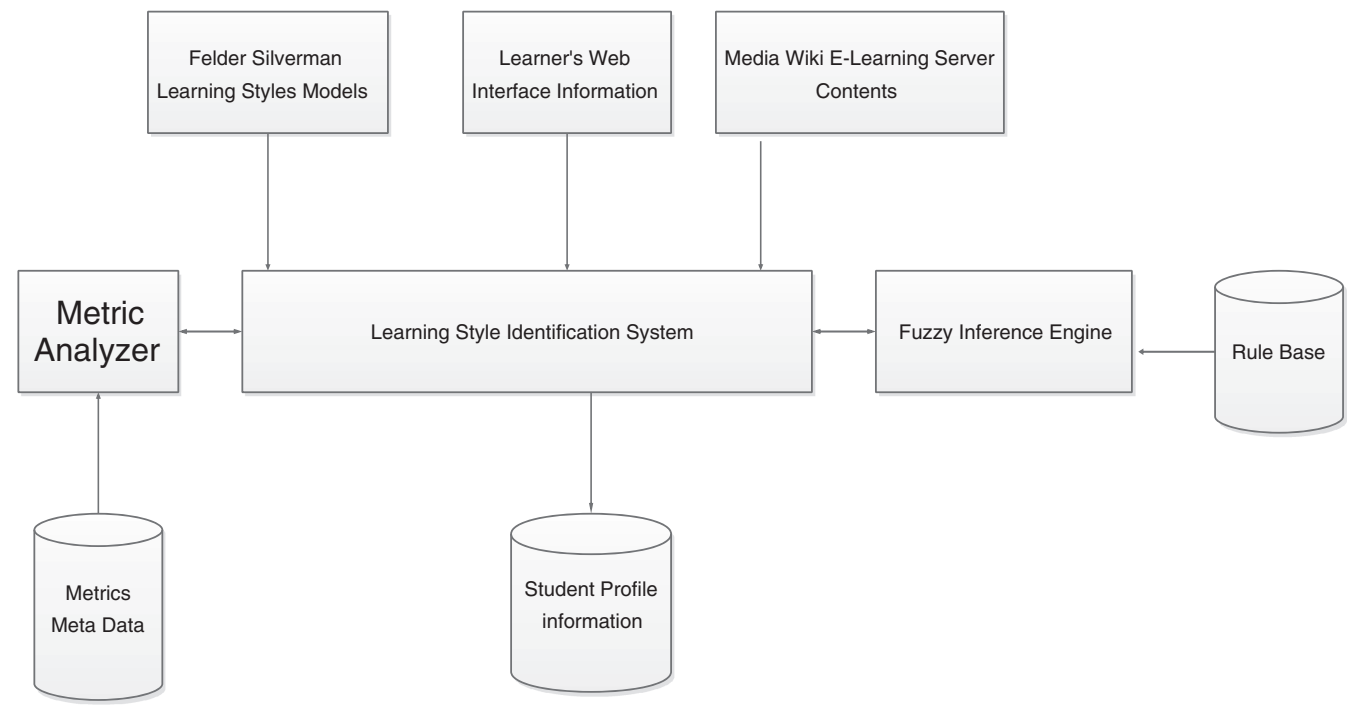

Figure 1. Proposed learning style identification model. 
Table 4. Parameters of learners web interface.

List of the parameters

Number of mouse movement in the $y$-axis

Ratio of document length to the time spent on a page

Ratio of images area to document length and scroll distance

Number of visits to a document

a rule base has been constructed which is fully loaded with input and output fuzzy rules. The learners' activities were carefully monitored and recorded for the learning styles prediction. These activities were recorded for analysis with respect to the parameters described in table 4 . According to the evaluation, the learners were classified into four kinds of learning styles namely active, medium active, medium reflective, and reflective.

\subsection{Metric analyzer}

The Learning style prediction of the proposed model is analyzed using various metrics described in table 5. These metrics include both the learners online web activity and some of their original profile information. Using the information from table 4, the metric analyzer present in the proposed system will analyze the learners' behavior and can aid in classifying the learners with respect to their learning styles.

\subsection{Rule base}

A rule based approach is proposed in this paper for the effective classification of learners which can also handle uncertain information is used. Moreover, this model aid in recommending and providing suitable E-Learning materials based on the identification of learning styles. The knowledge editor rule base consists of approximately 30 fuzzy rules for the prediction of learners based on their learning styles using online web activity information and offline profile information. The set of rules used in this proposed work is shown in Appendix A.

\subsection{Fuzzy inference engine}

The learners' membership degrees for Active/Reflective type of dimensions were experimented. By successfully providing the e-learning course materials of C programming language, the symmetric Gaussian membership function (Swati Chaudhari \& Manoj Patil 2014) for a Fuzzy set A, that represents the learning styles of the learners is represented by

$$
f(x ; \sigma, c)=e^{-\frac{(x-c)^{2}}{2 \sigma^{2}}} .
$$

Table 5. Metrics for learning styles prediction.

\begin{tabular}{ll}
\hline Online web information & Offline profile information \\
\hline $\begin{array}{l}\text { Number of mouse movement in the } y \text {-axis } \\
\text { Ratio of document length to the time spent on a page }\end{array}$ & Domain of interest \\
Ratio of images area to document length and scroll distance & $\begin{array}{l}\text { Educational background } \\
\text { Number of visits to a document }\end{array}$ \\
\hline
\end{tabular}




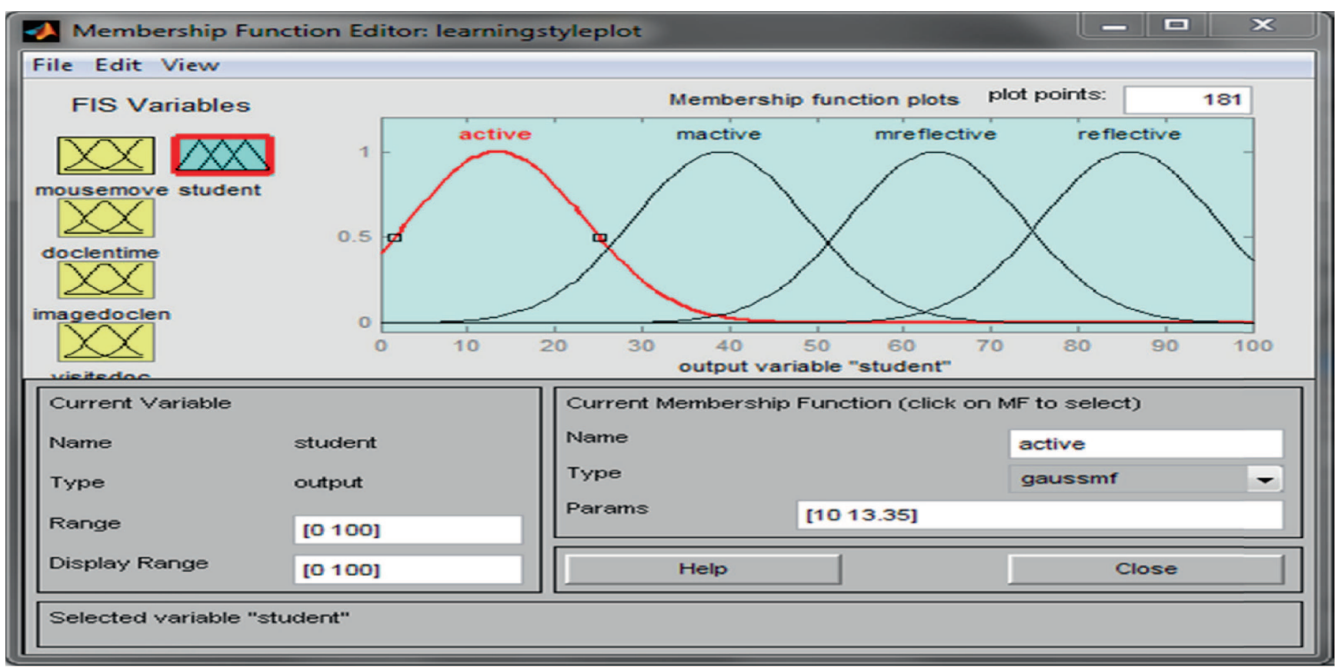

Figure 2. Symmetric Gaussian fuzzy function.

The parameters $\sigma$ (width) and $c$ (center) alter the width of the membership function curve of the Fuzzy set A, based on the input value $x$. This fuzzy set A represents the learning style, and the parameter $c$ denotes the mean of the membership function curve in this function (Chen \& Chang 2011).

The symmetric Gaussian fuzzy membership function used in the proposed model for the four categories of the learners namely active, medium active, medium reflective, and reflective is shown in figure 2. Based on the rule base developed in the proposed model, and on the application of the symmetric Gaussian fuzzy membership function described in Eq. 1, the learners could be predicted on their suitable learning styles.

\section{Performance evaluation}

The applicability of this model is tested in various E-Learning environments. Based on the authors' domain of interest, the proposed model is tested for learners interested in learning $\mathrm{C}$ programming language course with varying learning styles. The main objective of the model is to handle the uncertainty in the learners' behavior and to classify them accurately into four categories namely active, medium active, medium reflective, and reflective as present in the first dimension of Felder Silverman Learning Style model preferences. The described objective was tested and compared with the other existing algorithms and the results are shown in this section.

\subsection{Experimental set-up}

The learners during authentication procedure are solicited to provide their original profile information, including their age, gender, educational background, domain of interest, professional career, and hobbies. Subsequently, the learners are provided with various $\mathrm{C}$ programming language course contents from any of the e-learning servers like Media Wiki, Moodle, and Joomla. However, our experiments were based on the E-contents posted in Media Wiki e-learning servers. The experiments were carried out using 120 students of the Anna University from various branches, namely Civil Engineering, Mechanical Engineering, Computer Science and 
Engineering, and Electronics and Communication Engineering. The rule base included a set of 30 fuzzy rules for Learning Styles prediction. In this work, the inference for Learning Styles was done using Matlab R2009a. The experiments were repeated, analyzed and compared with the other existing models provided by Bergasa-Suso et al (2005), and Sanders \& Bergasa-Suso (2010). The proposed model is also compared with the traditional Bayesian Classification algorithm to test the significant difference in the accuracy of the proposed model. In all the repeated experiments, the Learning Styles of the learners were predicted based on their e-learning of C programming language course contents. However, this work is an ongoing work. The proposed work actually had its base from Felder Silverman learning style model preferences for Learning Style prediction and our work is limited to predicting the first dimension of learning styles only (Active/Reflective).

\subsection{Evaluation snapshot}

The experimental evaluation results shown below are obtained from the experiments conducted in this work on predicting the learning styles of the learners through offline profile information and online web activity information. The learners provide their complete information through a web interface. Subsequently, they E-Learn the C programming language course contents in the textual format available in Media Wiki e-learning servers. On successfully, collecting and recording this information, the metric analyzer analyzes for the available metrics to be used for learning styles prediction.

$X=$ Number of mouse movement in the y-axis

$Y=$ Ratio of document length to the time spent on a page

$Z=$ Ratio of image area to document length and scroll distance

In our experiments these metrics include both the profile information and the online web activity information. With the help of these metrics, the Fuzzy inference engine is responsible for classifying the learners into four categories, namely active, medium active, medium reflective, and reflective. This fuzzy inference engine makes use of a rule base fully loaded with 30 input and output fuzzy rules. The evaluation of the proposed model was estimated in terms of percentage of accuracy. Figure 3 shows the three dimensional view of the different kinds of the categorized learners namely active, medium active, medium reflective, and reflective. The $\mathrm{X}, \mathrm{Y}$, $\mathrm{Z}$ axis represents the first three parameters described in table 4 .

\subsection{Results and inference}

This work has been evaluated using accuracy percentage considering the total numbers of the sample population. Table 6 shows the comparative values obtained from this work with respect to the other existing algorithms for 30, 60, 90, and 120 numbers of learners. It is evident from the table that the proposed model shows an increased accuracy percentage compared to the other four algorithms, namely dead band algorithm, Bergassa algorithm, and Bayesian algorithm. This is due to the fact that the fuzzy inference engine has been used in this work which is efficient in handling the uncertain information. The accuracy of dead band algorithm proposed by Sanders \& Bergasa-Suso (2010) was higher when compared to the traditional Bayesian algorithm and the algorithm proposed by Bergasa-Suso et al (2005). However, Sanders \& Bergasa-Suso (2010) model introduced a new category called 'unknown' in his model for the learners who cannot be predicted precisely. 


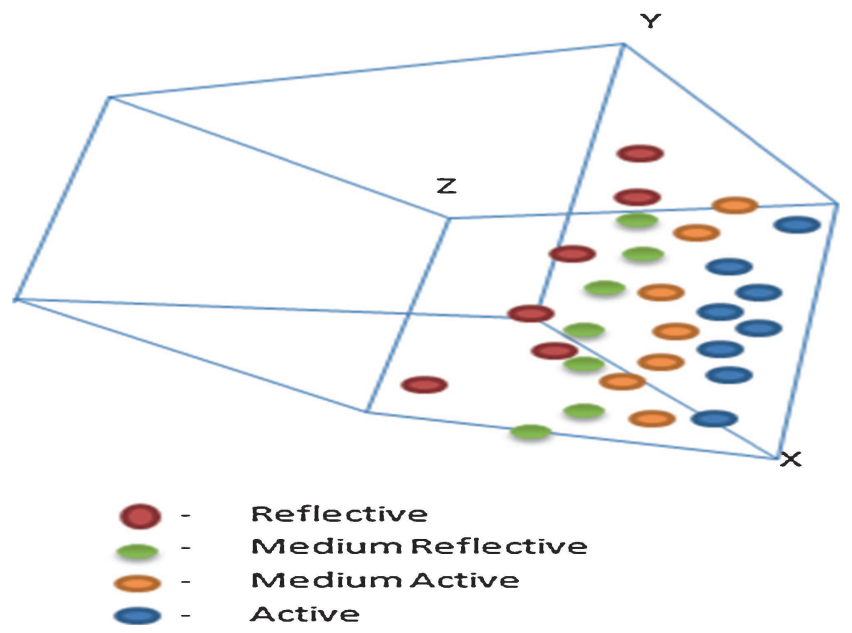

Figure 3. Three dimensional view of learners.

Table 6. Accuracy evaluation results for active/reflective dimension.

\begin{tabular}{lcccc}
\hline & \multicolumn{4}{c}{ Accuracy (\%) } \\
\cline { 2 - 5 } No. of users & $\begin{array}{c}\text { Fuzzy-logic based } \\
\text { Alg (Proposed) }\end{array}$ & $\begin{array}{c}\text { Deadband Alg } \\
\text { (Sanders \& } \\
\text { Bergasa-Suso 2010) }\end{array}$ & $\begin{array}{c}\text { Bergasa } \text { et al Alg } \\
\text { (Bergasa-Suso et al 2005) }\end{array}$ & $\begin{array}{c}\text { Bayesian Alg } \\
\text { (Dupre \& Tipler 2009) }\end{array}$ \\
\hline 30 & 59 & 52 & 48 & 42 \\
60 & 69 & 64 & 55 & 47 \\
90 & 84 & 75 & 65 & 52 \\
120 & 92 & 81 & 71 & 57 \\
\hline
\end{tabular}

Therefore, this work aims at resolving this 'unknown' category to be again classified into any one of the four categories namely active, medium active, medium reflective, and reflective, thereby increasing the accuracy percentage in predicting the learners based on their learning styles. Therefore, the objective of obtaining fine accuracy in the Learning Styles prediction of the uncertain learners who are learning through web environments has been achieved.

\section{Conclusion and future works}

In this paper, we propose a new fuzzy-logic based learning styles prediction based on e-learning of $\mathrm{C}$ programming language course contents. The main advantage of this proposed model is that it is efficient in handling the uncertainty in the learners' behavior through the information acquired from their profile information and online web user activities. The fuzzy inference engine used the rule base for accurately categorizing the learners even with incomplete information. However, this new work does not consider all the dimensions of Felder Silverman learning style model, but limited to the first dimension of Active/Reflective. The ongoing work aims at resolving the issues with the other dimensions of learning style model, namely sensing/intuitive, visual/verbal and sequential/global. Moreover, the proposed work was tested for a maximum of 120 online learners; however, further work will consider more participants, providing a more accurate representation of the entire population. 


\section{Appendix A}

\section{Fuzzy rules}

\begin{tabular}{|c|c|}
\hline Rule no & Fuzzy rules \\
\hline 1 & $\begin{array}{l}\text { If(mousemove is more) and (doclentime is more) and (imagedoclen is more) } \\
\text { and (visitsdoc is more) then (student is reflective) }\end{array}$ \\
\hline 2 & $\begin{array}{l}\text { If(mousemove is less) and (doclentime is lesss) and (imagedoclen is less) and } \\
\text { (visitsdoc is less) then (student is active) }\end{array}$ \\
\hline 3 & $\begin{array}{l}\text { If(mousemove is less) and (doclentime is less) and (imagedoclen is less) and } \\
\text { (visitsdoc is more) then (student is mactive) }\end{array}$ \\
\hline 4 & $\begin{array}{l}\text { If(mousemove is less) and (doclentime is less) and (imagedoclen is more) and } \\
\text { (visitsdoc is less) then (student is mactive) }\end{array}$ \\
\hline 5 & $\begin{array}{l}\text { If(mousemove is less) and (doclentime is more) and (imagedoclen is less) and } \\
\text { (visitsdoc is less) then (student is mactive) }\end{array}$ \\
\hline 6 & $\begin{array}{l}\text { If(mousemove is more) and (doclentime is less) and (imagedoclen is less) and } \\
\text { (visitsdoc is less) then (student is mactive) }\end{array}$ \\
\hline 7 & $\begin{array}{l}\text { If(mousemove is more) and (doclentime is more) and (imagedoclen is more) and } \\
\text { (visitsdoc is less) then (student is mreflective) }\end{array}$ \\
\hline 8 & $\begin{array}{l}\text { If(mousemove is more) and (doclentime is more) and (imagedoclen is less) and } \\
\text { (visitsdoc is more) then (student is mreflective) }\end{array}$ \\
\hline 9 & $\begin{array}{l}\text { If(mousemove is more) and (doclentime is less) and (imagedoclen is more) and } \\
\text { (visitsdoc is more) then (student is mreflective) }\end{array}$ \\
\hline 10 & $\begin{array}{l}\text { If(mousemove is less) and (doclentime is more) and (imagedoclen is more) and } \\
\text { (visitsdoc is more) then (student is mreflective) }\end{array}$ \\
\hline 11 & If(mousemove is less) and (doclentime is less) then (student is active) \\
\hline 12 & If(imagedoclen is more) and (visitsdoc is more) then (student is active) \\
\hline 13 & If(mousemove is more) and (doclentime is more) then (student is reflective) \\
\hline 14 & If(imagedoclen is more) and (visitsdoc is more) then (student is reflective) \\
\hline 15 & If(mousemove is less) and (doclentime is more) then (student is mreflective) \\
\hline 16 & If(mousemove is more) and (doclentime is less) then (student is rmactive) \\
\hline 17 & If(imagedoclen is less) and (visitsdoc is more) then (student is mactive) \\
\hline 18 & If(imagedoclen is more) and (visitsdoc is less) then (student is mreflective) \\
\hline 19 & $\begin{array}{l}\text { If(mousemove is less) and (doclentime is less) and (imagedoclen is more) and } \\
\text { (visitsdoc is more) then (student is mreflective) }\end{array}$ \\
\hline 20 & $\begin{array}{l}\text { If(mousemove is more) and (doclentime is less) and (imagedoclen is less) and } \\
\text { (visitsdoc is more) then (student is mreflective) }\end{array}$ \\
\hline 21 & $\begin{array}{l}\text { If(mousemove is more) and (doclentime is more) and (imagedoclen is less) and } \\
\text { (visitsdoc is less) then (student is mactive) }\end{array}$ \\
\hline 22 & $\begin{array}{l}\text { If(mousemove is less) and (doclentime is more) and (imagedoclen is more) and } \\
\text { (visitsdoc is less) then (student is mactive) }\end{array}$ \\
\hline 23 & If(mousemove is less) and (visitsdoc is less) then (student is active) \\
\hline 24 & If(mousemove is less) and (visitsdoc is more) then (student is mreflective) \\
\hline 25 & If(mousemove is more) and (visitsdoc is less) then (student is mactive) \\
\hline 26 & If(mousemove is more) and (visitsdoc is more) then (student is reflective) \\
\hline 27 & If(doclentime is less) and (imagedoclen is less) then (student is mreflective) \\
\hline 28 & If(doclentime is more) and (imagedoclen is more) then (student is mactive) \\
\hline 29 & If(doclentime is more) and (imagedoclen is less) then (student is active) \\
\hline 30 & If(doclentime is less) and (imagedoclen is more) then (student is reflective) \\
\hline
\end{tabular}




\section{References}

Acampora G, Cadenas J M, Loia V and Ballester E M 2011 A multi-agent memetic system for human-based knowledge selection. IEEE Trans Syst. Man and Cybernetics, Part A: Systems and Humans 41(5)

Almohammadi K and Hagras H 2013 An interval Type-2 fuzzy logic based system for customised knowledge delivery within pervasive e-learning platforms. In: Proceedings of IEEE international conference on systems, man, and cybernetics (SMC), 2872-2879

Anozie N and Junker B W 2006 Predicting end-of-year accountability assessment scores from monthly student records in an online tutoring system. In: Proceedings of AAAI workshop on educational data mining, Menlo Park, 1-6

Antunes C 2008 Acquiring background knowledge for intelligent tutoring systems. In: Proceedings of international conference on educational data mining, Montreal, 18-27

Avouris N, Komis V, Fiotakis G, Margaritis M and Voyiatzaki E 2005 Why logging of fingertip actions is not enough for analysis of learning activities. In: Proceedings of AIED conference on workshop usage analysis learning system, Amsterdam, 1-8

Ayers E, Nugent R and Dean N 2009 A comparison of student skill knowledge estimates. In: Proceedings of international conference on educational data mining, Cordoba, 1-10

Ba-Omar H, Petrounias I and Anwar F 2007 A framework for using web usage mining for personalize E-learning. In: Proceedings of international conference on advanced learning technologies, Niigata, 937-938

Baker R, Corbett A and Koedinger K 2004 Detecting student misuse of intelligent tutoring systems. In: Proceedings of international conference on intelligence tutoring system, Alagoas, 531-540

Barnes T 2005 The q-matrix method: Mining student response data for knowledge. In: Proceedings of AAAI workshop educational data mining, Pittsburgh, 1-8

Beck J E, Baker R, Corbett A T, Kay J, Litman D J, Mitrovic T and Ritter S 2004 Analyzing student tutor interaction logs improve educational outcomes. Presented at the 7th international conference on workshop, Alagoas

Bergasa-Suso J, Sanders D A and Tewkesbury G E 2005 Intelligent browser-based systems to assist Internet users. IEEE Trans. Educ. 48(4): 580-585

Butler K 1986 A learning and teaching style in theory and practice. Columbia: Learner's Dimension

Carver C A, Howard R A and Lane W D 1999 Enhancing student learning through hypermedia courseware and incorporation of student learning styles. IEEE Trans. Educ. 42(1): 33-38

Cornwell J M and Manfredo P A 1994 Kolb learning style theory revisited. Educ. Psychol. Meas. 54(2): 317-327

Chen Y and Weng C 2009 Mining fuzzy association rules from questionnaire data. Knowl. Based Syst. J. 22(1): 46-56

Chen S-M and Chang Y-C 2011 Weighted fuzzy rule interpolation based on GA-based weight-learning techniques. IEEE Trans. Fuzzy Syst. 19(4): 729-744

Chen C, Duh L and Liu C 2004 A personalized courseware recommendation system based on fuzzy item response theory. In: Proceedings of IEEE international conference on E-Technology, E-Commerce, EService, Washington, 305-308

Chen G, Liu C, Ou K and Liu B 2000 Discovering decision knowledge from web log portfolio for managing classroom processes by applying decision tree and data cube technology. J. Educ. Comput. Res. 23(3): 305-332

Dekker G W, Pechenizkiy M and Vleeshouwers J M 2009 Predicting students drop out: A case study. In: Proceedings of international conference on educational data mining, Cordoba, 41-50

Dias S B and Diniz J A 2013 FuzzyQoI Model: A fuzzy logic-based modelling of users' quality of interaction with a learning management system under blended learning. Elsevier COMPUT EDUC 69: 3859

Dunn R 1990 Understanding the Dunn and Dunn learning style model and the need for individual diagnosis and prescription. Read Write Learn Disabil. 6: 223-247

Dunn R and Dunn K 1989 Learning style inventory. Lawrence: Price Systems 
Dupre Maurice J and Tipler Frank T 2009 New axioms for bayesian probability. International Society for Bayesian Analysis 3: 599-606

Elhag M F and Ahmed A H A 2013 Intelligent system for selecting Optimum Instructional style(s) based on fuzzy logic to develop a courseware (ISSIDC). In: Proceedings of international conference on computing, electrical and electronics engineering (ICCEEE), 518-524

Felder R M and Silverman L K 1988 Learning styles and teaching styles in engineering education. Eng. Educ. 78(7): 674-681

Fleming N D 2001 Teaching and learning styles: VARK strategies. N.D. Fleming Christchurch

Garcia-Valverde T, Garcia-Sola A, Gomez-Skarmeta A and Botia J A 2012 An adaptive learning fuzzy logic system for indoor localisation using Wi-Fi in Ambient Intelligent Environments. In: Proceedings of IEEE international conference on fuzzy systems (FUZZ-IEEE), 1-8

Gardner H 1999 Intelligence reframed: Multiple intelligences for the 21st century. New York: Basic Books

Gilbert J E and Han C Y 1999 Adapting instruction in search of a significant difference. J. Netw. Comput. Appl. 22(3): 149-160

Gregorc A F 1985 Inside styles: Beyond the basics. Maynard: Gabriel sys

Gregorc A F and Ward H 1977 BA new definition for individual: Implications for learning and teaching. NASSP Bull. 401(6): 20-23

Guennoun K and Drira K 2006 Using graph grammars for interaction style description: Applications for service-oriented architectures. IJCSSE 21(2)

Honey P and Mumford 2000 The learning styles helper's guide. Maidenhead: Peter Honey Publications Ltd

Jackson C 2002 Manual of the learning styles profiler. Available at http://www.cymeon.com

Jegatha Deborah L, Baskaran R and Kannan A 2014 Learning Styles assessment and theoretical origin in an E-learning scenario: a survey. Artif. Intell. Rev 42(4): 801-819

Jegatha Deborah L, Baskaran R and Kannan A 2011a Construction of ontology using computational linguistics for E-learning. In: Proceedings of the 2nd international conference on visual informatics, Kualalumpur. Springer-Lecture Notes in Computer Science, pp 50-63

Jegatha Deborah L, Karthika V, Baskaran R and Kannan A 2011b Deontic based ontology matching for conflict resolution between text documents. In: Proceedings of the international conference on information processing, Bangalore. Springer-Communications in Computer and Information Science, 526-535

Kakoty S, Lal M and Sarma S K 2012 Fuzzy expert logic to evaluate learner's expertise level in e-learning environment. In: Proceedings of IEEE international conference on advanced communication control and computing technologies (ICACCCT), 148-152

Kolb A Y and Kolb D A 2005 Learning styles and learning spaces: enhancing Experiential learning in higher education. Acad. Manag. Learn Educ. 4(2): 193-212

Lu F, Li X, Liu Q, Yang Z, Tan G and He T 2007 Research on personalized E-learning system using fuzzy set based clustering algorithm. In: Proceedings of international conference on computer science, Beijing, $587-590$

McCaulley M H 2000 Myers-Briggs type indicator: A bridge between counseling and consulting. Consult . Psychol. J. Practice Res. 52: 117-132

Nebot A, Castro F, Vellido A and Mugica F 2006 Identification of fuzzy models to predict students performance in an E-learning environment. In: Proceedings of international conference on web-based education, Puerto Vallarta, 74-79

Papanikolaou K A, Grigoriadou M, Magoulas G D and Kornilakis H 2002 Towards newforms of knowledge communication: The adaptive dimension of a Web-based learning environment. Comput. Educ. 39(4): 333-360

Paredes P and Rodriguez P 2002 Considering sensing-intuitive dimension to exposition-exemplification in adaptive sequencing. In: Proceedings AH2002 Conf. 556-559

Pittenger D J 2005 Cautionary comments regarding the Myers-Briggs type indicator. Consult. Psychol. J. Practice Res. 57(3): 210-221

Sanders D A 1993 System specification 2. Microprocess. Microprogram. 38(1-5): 833 
Sanders D A and Bergasa-Suso J 2010 Inferring learning style from the way students interact with a computer user interface and the WWW. IEEE Trans. Educ. 53(4): 613-620

Swati Chaudhari and Manoj Patil 2014 Study and review of fuzzy inference systems for decision making and control. AIJRSTEM 5(1): 88-92

Tang Zhe, Er Meng Joo and Qi Fang 2011 Dynamic fuzzy neural network for the intelligent control of a humanoid robot. IJCSSE 26(3)

Triantafillou E, Pomportsis A and Georgiadou E 2002 AES-CS: Adaptive educational system base on cognitive styles. In: Proceedings AH2002 Workshop, 10-20

Wilges B, Mateus G P, Nassar S M and Bastos R C 2012 Integration of BDI agent with fuzzy logic in a virtual learning environment. IEEE Trans. Latin Am. (Revista IEEE America Latina), 10(1)

Yang T-C, Hwang G-J and Yang S J-H 2013 Development of an adaptive learning system with multiple perspectives based on students' learning styles and cognitive styles. Educational Technology \& Society 16(4): 185-200 